\title{
Synthesis, characterization and complexation properties of a polystyrene resin containing $\beta$-hydroxydithiocinnamic acid
}

\author{
Chuen-Ying Liu and Jiin-Jou Lih \\ Department of Chemistry, National Taiwan University, Taipei, Taiwan, Republic of China
}

\author{
Synthese, Charakterisierung \\ und Komplexierungseigenschaften eines \\ $\beta$-Hydroxydithiozimtsäure-haltigen Polystyrolharzes
}

\begin{abstract}
Summary. A new chelating resin was synthesized from a macroreticular polystyrene-divinylbenzene copolymer incorporating the $\beta$-hydroxydithiocinnamic acid functional group. Some properties, such as the water regain, hydrogen capacity, sulfur content, dissociation constant and the metal capacity of the resin were determined. The formation constants for $\mathrm{Cd}(\mathrm{II})$ and $\mathrm{Cu}(\mathrm{II})$ resin complex were determined to be $10^{1.10}$ and $10^{2.44}$, respectively. The results of the $\mathrm{pH}$-dependence of the adsorption capacity and the trace metal ion uptake showed that the synthesized resin was highly selective for silver(I), mercury(II), gold(III) and platinum(IV) in strongly acidic aqueous solution.
\end{abstract}

\section{Introduction}

The lack of selectivity of the conventional ion-exchange resins has led to the discovery and development of a new kind of specific and selective resins. These resins are in fact polymeric complexing and chelating compounds. Despite the increasing utility and application of these resins in separations, preconcentration and recovery of trace metal ions, in catalysis, organic synthesis, nuclear chemistry, water and waste water treatment, pollution control and industrial processes, hydrometallurgy, polymer drug grafts and various miscellaneous applications in analytical chemistry, the development of their coordination chemistry has remained rather slow [1]. In view of the above mentioned facts and in continuation of earlier work in the field of preparation of selective ion-exchange resins, a $\beta$-hydroxydithiocinnamic acid functional group containing resin was synthesized. $\beta$-Hydroxydithiocinnamic acid, a new chelating agent could form either four-membered chelate rings through two sulfur atoms as very useful analytical reagents (dithiocarbamate [2-6] and xanthate [7-9]) or form sixmembered chelate rings through oxygen and sulfur atoms with metal ions. Based on the above chelating properties, it was expected that a $\beta$-hydroxydithiocinnamic acid group incorporated into a resin would be advantageous. This paper

Offprint requests to: Chuen-Ying Liu describes the synthesis and basic characteristics of such a resin. In addition, some properties and the chelating behaviour of the synthesized new resin are also discussed.

\section{Experimental}

Model reactions. $\beta$-Hydroxydithiocinnamic acid $(\beta$ HDTCA) was prepared by the method of Larsson and Lawesson [10] with slight modification. 0.015 mole of acetophenone and 0.025 mole of carbon disulfide in $35 \mathrm{ml}$ benzene were added dropwise to 0.05 mole of t-BuOK in $45 \mathrm{ml}$ benzene. Stirring was continued at $0^{\circ} \mathrm{C}$ for $1 \mathrm{~h}$. Then the mixture was poured into water, the benzene phase removed, the aqueous layer acidified with $2.5 \mathrm{~mol} / 1 \mathrm{H}_{2} \mathrm{SO}_{4}$. The precipitate obtained was collected onto a filter, and recrystallized from methanol giving a higher than $70 \%$ yield of the acid (m.p. $70^{\circ} \mathrm{C}$ ).

Preparation of $\beta$-hydroxydithiocinnamate resin. The polystyrene-divinylbenzene, XAD-4 (Rohm and Haas, Philadelphia, Pa, USA) macroreticular resin was used as starting material. To $10 \mathrm{~g}$ of XAD-4 resin $90 \mathrm{~g}$ of anhydrous aluminium trichloride and $50 \mathrm{ml}$ of petroleum ether were added $\left(100^{\circ}-140^{\circ} \mathrm{C}\right)$. Then $50 \mathrm{ml}$ of $1: 1$ petroleum ether/acetic anhydride were added over a period of $30 \mathrm{~min}$ through an addition funnel, and the resulting mixture was refluxed at $83^{\circ} \mathrm{C}$ for $5 \mathrm{~h}$. This product (I in Scheme 1) was cooled to room temperature and hydrolyzed in $12 \mathrm{~mol} / 1$ hydrochloric acid and ice. It was then collected by suction filtration and washed sequently with $15 \mathrm{~mol} / 1$ ammonium hydroxide, $12 \mathrm{~mol} / 1 \mathrm{hydrochloric}$ acid, water and acetone. These procedures were repeated to obtain a higher yield. The product was then slurried in $50 \mathrm{ml}$ of petroleum ether to which $20 \mathrm{~g}$ of potassium t-butoxide and $40 \mathrm{ml}$ of carbon disulfide were added. The mixture was reacted at $43^{\circ} \mathrm{C}$ for $5 \mathrm{~h}$. The final product was collected by suction filtration and washed sequently with $2.5 \mathrm{~mol} / \mathrm{l}$ sulfuric acid, water and acetone.

Determination of the dissociation constant of the resin. Various amounts of $0.100 \mathrm{~mol} / 1$ sodium hydroxide were added to each $0.2 \mathrm{~g}$ resin sample. The ionic strength of $1.0 \mathrm{~mol} / \mathrm{l}$ and the $25 \mathrm{ml}$ final volume were adjusted by the addition of a calculated quantity of $2.5 \mathrm{~mol} / 1$ sodium chloride and water. The systems were left to equilibrate for 2 days at $25^{\circ} \mathrm{C}$. Then, the $\mathrm{pH}$ of the solution phase was measured and some of the other parameters were determined as following: 


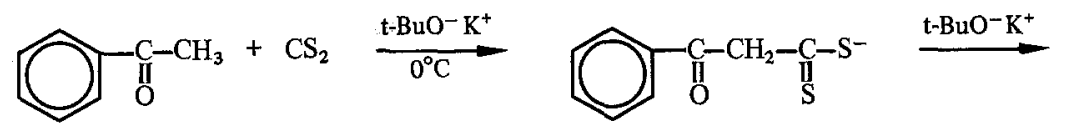<smiles>CC(C)c1cccc(C(O)=CC(=S)S)c1</smiles>

Pet. ether $\left(100^{\circ}-140^{\circ} \mathrm{C}\right)$

$\mathrm{XAD}-4$<smiles>CC(=O)c1cc(I)ccc1I</smiles><smiles>Cc1ccc(C)c(C(O)=CC(=S)S)c1</smiles>

1. Determination of the amount of counter-ions in the resin phase: The sodium ions were eluted from the resin with $20 \mathrm{ml}$ of $0.1 \mathrm{~mol} / 1$ nitric acid collected in a $50 \mathrm{ml}$ volumetric flask. The resin was washed free of chloride with water and the solution made up to the mark. The amount of chemically bound sodium ions was obtained by titration of the acid left in the solution, with $0.1 \mathrm{~mol} / \mathrm{l}$ sodium hydroxide and that of the invasive sodium chloride from a Volhard determination.

2. Determination of the hydrogen ion capacity: To obtain the hydrogen ion capacity, the amount of chemically bound counter-ions was plotted against the $\mathrm{pH}$ of the resin phase.

Determination of metal ion capacity and trace metal ion uptake. $\mathrm{pH}$-Dependence of metal-ion capacity and trace metal ion uptake of the $\beta$-HDTCA resin were evaluated as previously by a batch equilibration technique [11]. Briefly, metal ion was loaded on $0.3 \mathrm{~g}$ of resin. After equilibration, the solid was filtered off and washed with water. The amount of metal ion in the filtrate was determined titrimetrically or spectrophotometrically.

Determination of the complex-decomposition $p H$. An air-dry sample of the resin was weighed into an ion-exchange column $(160 \times 5 \mathrm{~mm}$ i.d. $)$. The column was conditioned with acetic acid-sodium acetate buffer. Then, $0.2 \mathrm{mmol}$ copper ion or $0.2 \mathrm{mmol}$ cadmium ion was applied on the top of the column. The metal ion sorbed was then eluted with 0.01 or $0.02 \mathrm{~mol} / 1$ hydrochloric acid and $4 \mathrm{ml}$ fractions of the effluent were collected. The $\mathrm{pH}$ was measured and the metal ion content in each fraction was determined spectrophotometrically.
Scheme 1

Synthesis of $\beta$-hydroxydithiocinnamic acid

Scheme 2

Synthesis of $\beta$-hydroxydithiocinnamate resin

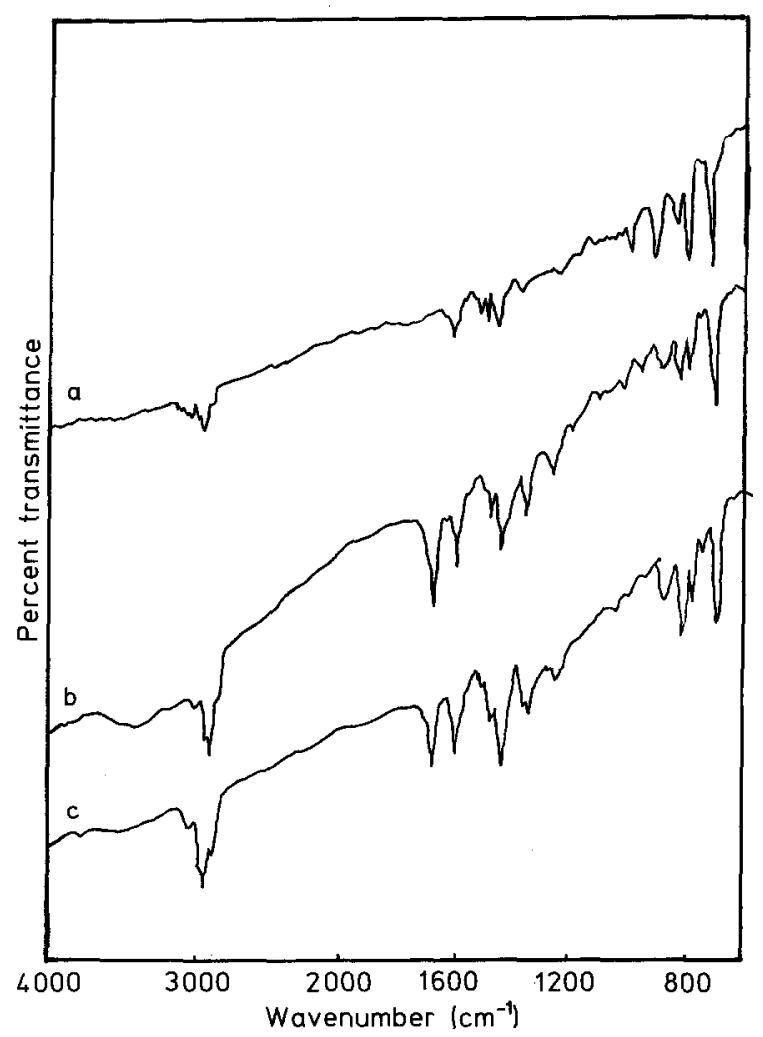

Fig. 1. Infrared spectra. $a \mathrm{XAD}-4$, polystyrene-divinylbenzene copolymer; $b$ intermediate product; $c \beta$-hydroxydithiocinnamate resin 


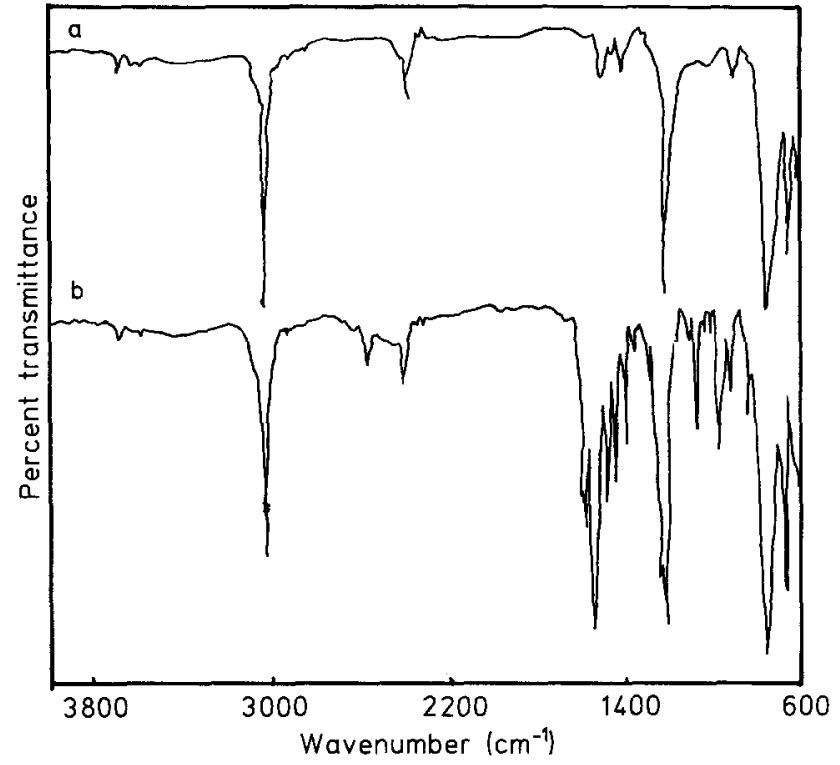

Fig. 2. Infrared spectra. $a$ Chloroform; $b$ monomeric $\beta$-hydroxydithiocinnamic acid

\section{Results and discussion}

Preparation of the $\beta$-hydroxydithiocinnamate resin. It was apt to synthesize $\beta$-hydroxydithiocinnamic acid (model compound) (as shown in Scheme 1) and the yield was very high (higher than $70 \%$ ). Hence, in the preparation of the $\beta$ hydroxydithiocinnamate resin, the procedures were the same as those of the model compound (as shown in Scheme 2).

The characterization of the synthesized resin is of importance in the application of this material to actual analytical samples and for the prediction of resin behaviour in the application. In order to elucidate the structure of the synthesized resin, the infrared spectra obtained with $\mathrm{KBr}$ pellets were recorded after each step in the syntheses. Figure $1 \mathrm{a}$ is the spectrum of the starting material, XAD-4, polystyrenedivinylbenzene copolymer. Figure $1 \mathrm{~b}$ shows the spectrum of the intermediate substance; the prominent band $(-\mathrm{C}=\mathrm{O})$ appears at $1685 \mathrm{~cm}^{-1}$ and the intensity of the band increased as the repeatability of the reaction increased. Figure $1 \mathrm{c}$ is the spectrum of the final product, $\beta$-hydroxydithiocinnamate resin. The absorption spectrum of this resin was in accordance with that of the monomeric $\beta$-hydroxydithiocinnamic acid which was obtained from chloroform solution (Fig. 2b) at 1603,1240, and $1070 \mathrm{~cm}^{-1}$, except the peak of $-\mathrm{SH}$ at $2571 \mathrm{~cm}^{-1}$ which was also known to be absent in the solid form of the thiol compound [12].

For evaluation of the dissociation constant of the chelating resin, some parameters, such as $\bar{\alpha}^{*}, \overline{\mathrm{G}_{\mathrm{K}}}, \overline{\mathrm{G}_{1}},[\mathrm{G}]$, $[\mathrm{H}],[\overline{\mathrm{H}}], \mathrm{Q}, \overline{\mathrm{H}_{2}} \mathrm{O}$, etc. should be established [13], where

$\alpha^{*}$ : the mole fraction of the non-protonated base in the resin phase,

$\overline{\mathrm{G}_{\mathrm{K}}}$ : the amount of chemically bound counter ion,

$\overline{\mathrm{G}_{1}}$ : the amount of ions migrated into the resin lattice,

$[G]$ : the concentration of the counter ions in the resin phase,

$[\mathrm{H}]$ : the proton activity in the solution phase,

$[\overline{\mathrm{H}}]$ : the proton activity in the resin phase,

Q: the hydrogen capacity of the resin,

$\overline{\mathrm{H}_{2} \mathrm{O}}$ : the water content of the resin.

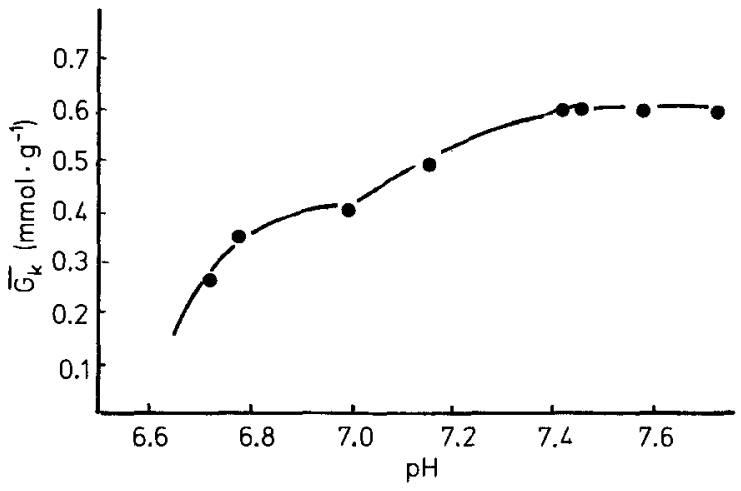

Fig. 3. Determination of the hydrogen capacity of the $\beta$-hydroxydithiocinnamate resin
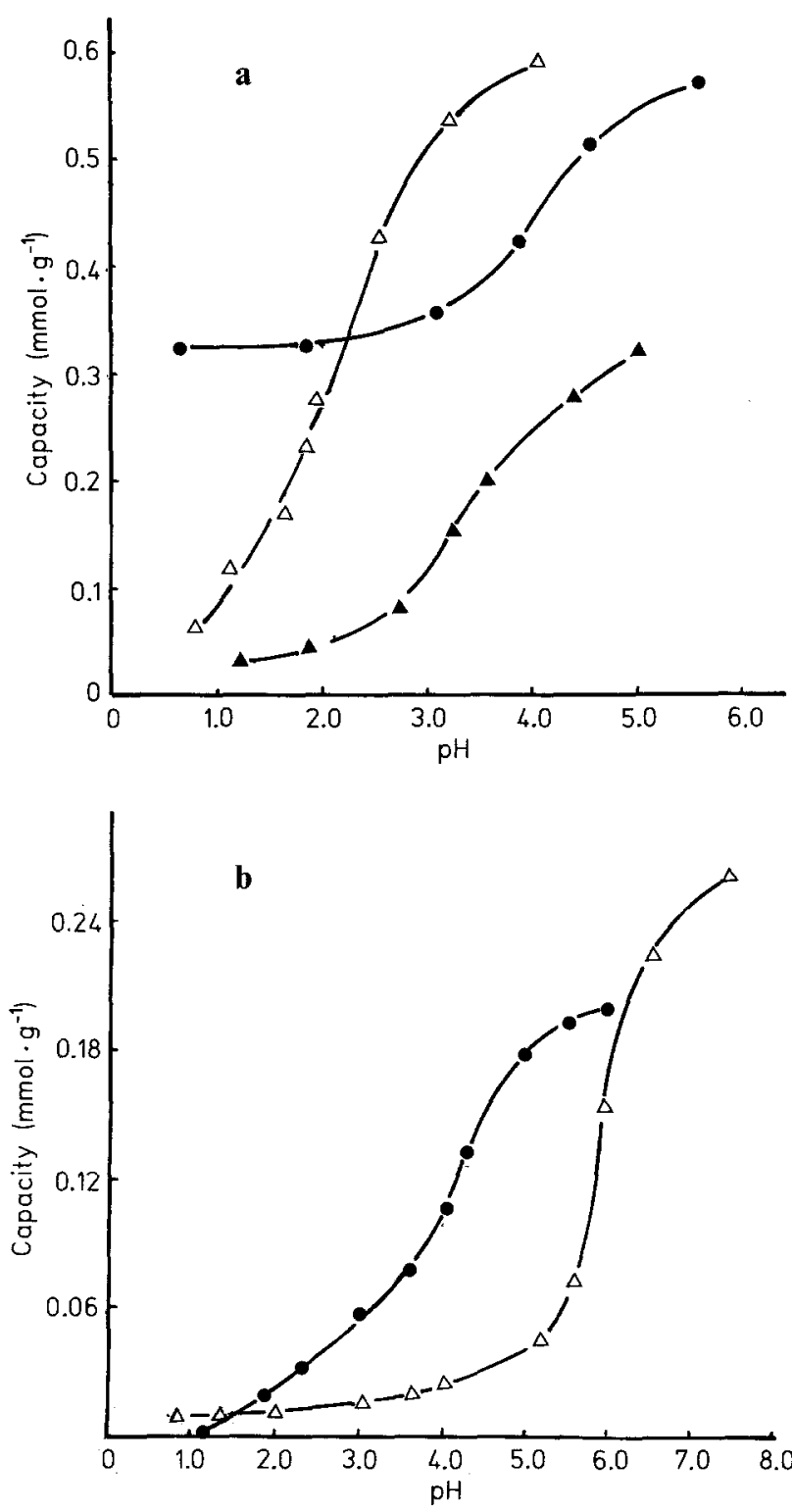

Fig. 4. a Total capacity vs. $\mathrm{pH}$ curves for metal ions on the $\beta$-hydroxydithiocinnamate resin: $\operatorname{Ag}(\mathrm{I}) \quad \boldsymbol{\Delta}-\boldsymbol{\Lambda} ; \mathrm{Hg}(\mathrm{II})$ $-0 ; \mathrm{Fe}(\mathrm{III}) \triangle \longrightarrow \triangle$. b Total capacity vs. $\mathrm{pH}$ curves for metal ions on the $\beta$-hydroxydithiocinnamate resin: Ni(II) $\triangle \sim \triangle \mathrm{Pb}(\mathrm{II})$ 
Table 1. Determination of the dissociation constants of $\beta$-hydroxydithiocinnamate resin

\begin{tabular}{lcccccc}
$\overline{\mathrm{pH}}$ & $\overline{\mathrm{G}_{\mathrm{K}}}$ & $\overline{\mathrm{G}_{\mathrm{I}}}$ & {$[\mathrm{G}]$} & $\overline{\mathrm{pH}}$ & $\overline{\alpha^{*}}$ & $\mathrm{pK}_{\mathrm{a}}$ \\
\hline 6.35 & 0.27 & 0.06 & 0.43 & 6.72 & 0.45 & 6.44 \\
6.50 & 0.36 & 0.08 & 0.55 & 6.76 & 0.58 & 6.62 \\
6.80 & 0.40 & 0.09 & 0.64 & 6.99 & 0.67 & 6.68 \\
7.03 & 0.49 & 0.10 & 0.76 & 7.15 & 0.81 & 6.40
\end{tabular}

Amount of resin: $0.2 \mathrm{~g}$; volume of solution: $25 \mathrm{ml}$; ionic strength: $1.0 \mathrm{~mol} / 1$; water regain: $0.77 \mathrm{~g} \mathrm{~g}^{-1}$; temperature: $25^{\circ} \mathrm{C}$

Table 2. Physical and chemical properties of $\beta$-hydroxydithiocinnamate resin

$\begin{array}{ll}\text { Particle size } & 100-200 \mathrm{mesh} \\ \text { Water regain } & 0.77 \mathrm{~g} \mathrm{~g}^{-1} \\ \text { Sulfur content } & 1.20 \mathrm{mmol} \mathrm{g}^{-1} \\ \text { Hydrogen capacity } & 0.60 \mathrm{mmol} \mathrm{g}^{-1} \\ \text { pK }_{\mathrm{a}} & 6.54 \\ \text { Cadmium capacity (pH 5.0) } & 0.02 \mathrm{mmol} \mathrm{g}^{-1} \\ \text { Copper capacity (pH 5.0) } & 0.05 \mathrm{mmol} \mathrm{g}^{-1} \\ \text { Iron capacity (pH 4.0) } & 0.60 \mathrm{mmol} \mathrm{g}^{-1} \\ \text { Lead capacity (pH 5.8) } & 0.20 \mathrm{mmol} \mathrm{g}^{-1} \\ \text { Mercury capacity (pH 5.6) } & 0.59 \mathrm{mmol} \mathrm{g}^{-1} \\ \text { Nickel capacity (pH 7.4) } & 0.29 \mathrm{mmol} \mathrm{g}^{-1} \\ \text { Silver capacity (pH 4.4) } & 0.30 \mathrm{mmol} \mathrm{g}^{-1} \\ \log K_{\mathrm{f}} \text { (Cd(II)) } & 1.10 \\ \log K_{\mathrm{f}} \text { (Cu(II)) } & 2.44\end{array}$

Table 3. Experimental data and results of determining the stability constants of $\beta$-hydroxydithiocinnamate resin-metal complexes

\begin{tabular}{lll}
\hline & $\mathrm{Cd}(\mathrm{II})$ & $\mathrm{Cu}(\mathrm{II})$ \\
\hline Initial pH for the complexation & 8.0 & 5.5 \\
Amount of metal ion (mmol) & 0.2 & 0.2 \\
Concentration of eluent (HCl) (mol/1) & 0.02 & 0.01 \\
DpH & 5.44 & 4.10 \\
$\log K_{\mathrm{MR}}$ & 1.10 & 2.44 \\
\hline
\end{tabular}

The water regain of the resin determined by the method of centrifuging [14] was $0.776 \mathrm{~g} \mathrm{~g}^{-1}$. The plot of $\overline{\mathrm{G}_{\mathrm{K}}}$ vs. $\mathrm{p} \overline{\mathrm{H}}$ (Fig. 3) showed that the hydrogen capacity was $0.6 \mathrm{mmol}$ $\mathrm{g}^{-1}$. Some other parameters determined are listed in Table 1. From this table, the dissociation constant of the resin could be calculated [13]. Due to the steric hindrance and the hydrophobicity of the polymer matrix, the $\mathrm{pK}_{\mathrm{a}}$ of the synthesized resin, 6.54 , is rational in comparison with that of the monomer, 5.44 [15].

Complexation properties of the chelating resin. The metal ion absorption capacities of the resin at various $\mathrm{pH}$ values were determined in the presence of an excess amount of metal ion with the results given in Fig. $4 \mathrm{a}, \mathrm{b}$. The maximum capacities for cadmium(II), copper(II), iron(III), lead(II), mercury(II), nickel(II) and silver(I) are listed in Table 2. This table also shows the other physical and chemical properties of the synthesized resin. For mercuric ion, the maximum capacity was ca. $0.6 \mathrm{mmol}$ per gram resin (Table 2) which was close to the ligand content, $0.6 \mathrm{mmol}$ per gram resin (from elemental analysis). Hence, we can say that the synthesized resin seems to form an one to one complex with the mercuric ion.
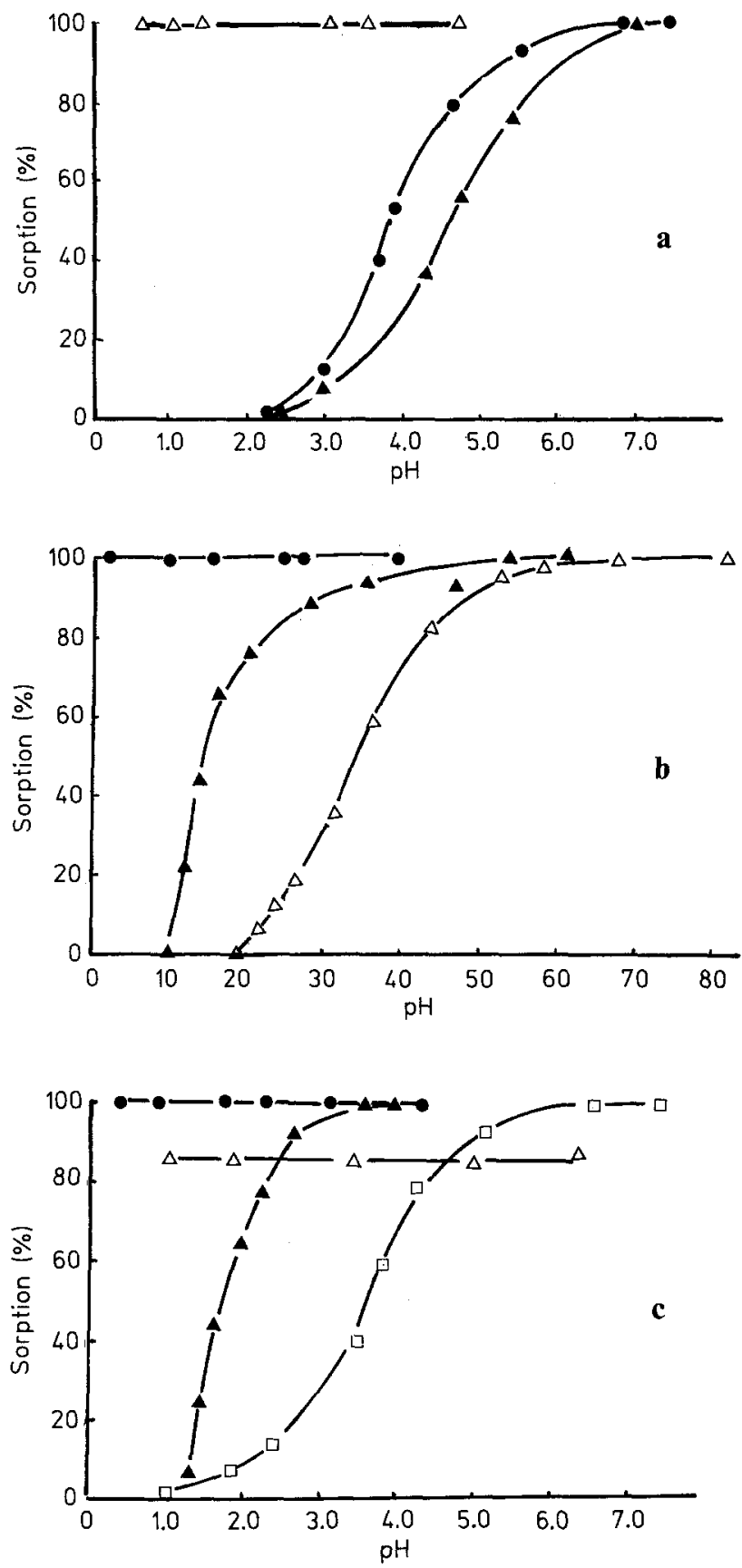

Fig. 5. a Metal recovery as a function of $\mathrm{pH}$ on the $\beta$-hydroxydithiocinnamate resin: $\mathrm{Cd}(\mathrm{II})-\longrightarrow \mathrm{Hg}(\mathrm{II}) \triangle \longrightarrow \triangle$;

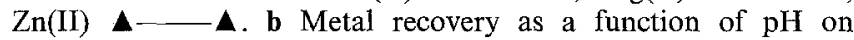
the $\beta$-hydroxydithiocinnamate resin: Au(III) -

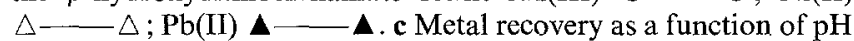
on the $\beta$-hydroxydithiocinnamate resin: $\mathrm{Ag}(\mathrm{I}) \triangle \longrightarrow \triangle \mathrm{Cu}(\mathrm{II})$ $\square \_-\square ; \mathrm{Fe}(\mathrm{III}) \boldsymbol{\Delta}-\boldsymbol{\Delta} ; \mathrm{Pt}(\mathrm{IV})$

To determine the trace metal ion uptake, studies were carried out in which the resin was present in excess of the metal ion. The uptake of most of the metal ions tested increased with $\mathrm{pH}$, except that of silver(I), mercury(II), gold(III) and platinum(IV) (Fig. 5a-c). The order of sorption is $\mathrm{Pt}(\mathrm{IV}) \cong \mathrm{Au}(\mathrm{III}) \cong \mathrm{Hg}$ (II) $>\mathrm{Ag}$ (I) $>\mathrm{Pb}$ (II) $>$ $\mathrm{Fe}(\mathrm{III})>\mathrm{Ni}(\mathrm{II})>\mathrm{Cu}(\mathrm{II})>\mathrm{Cd}(\mathrm{II})>\mathrm{Zn}$ (II). The sorption mechanism is still not completely elucidated. However, the 


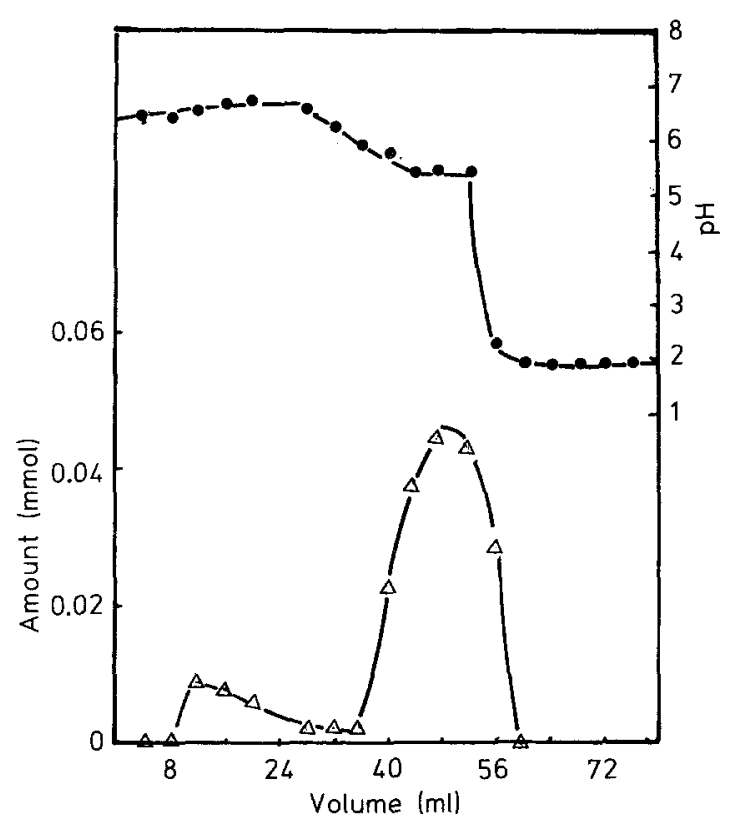

Fig. 6. Changes in $\mathrm{pH}$ and cadmium(II) content of the collected fractions as a function of the volume of the eluent

high capacity for mercury suggests that the synthesized resin shows high affinity and selectivity for soft metal ions.

For the calculation of the stability constant $\left(K_{\mathrm{MR}}\right)$ of the metal-chelating resin complexes, the following equation was used [16]:

$\log K_{\mathrm{MR}}=\log \beta_{\mathrm{j}}^{\prime}-n \cdot \mathrm{DpH}$

where $\beta_{j}^{\prime}$ is the apparent cumulative protonation constant of the ligand and $n$ is the number of protons bound to the ligand. In order to calculate $K_{\mathrm{MR}}$, the protonation constant and the DpH-values should be measured. Figures 6 and 7 show the changes in the $\mathrm{pH}$ and the metal content of the collected fractions as a function of the volume of the eluent. From this, the $\mathrm{DpH}$-values for $\mathrm{Cd}(\mathrm{II})$ and $\mathrm{Cu}(\mathrm{II})$ were found to be 5.44 and 4.10 , respectively. The experimental data and the apparent stability constants of the metal-resin complexes calculated by means of Eq. (1) are given in Table 3. The low formation constants of the copper-resin complex and the cadmium-resin complex are consistent with the results of copper and cadmium capacity shown in Table 2 .

\section{Conclusion}

$\beta$-Hydroxydithiocinnamate resin may be expected to be very useful as a chelating resin for the collection and concentration of noble metals from very dilute solutions or the separation of noble metals from each other or from other metal ions.

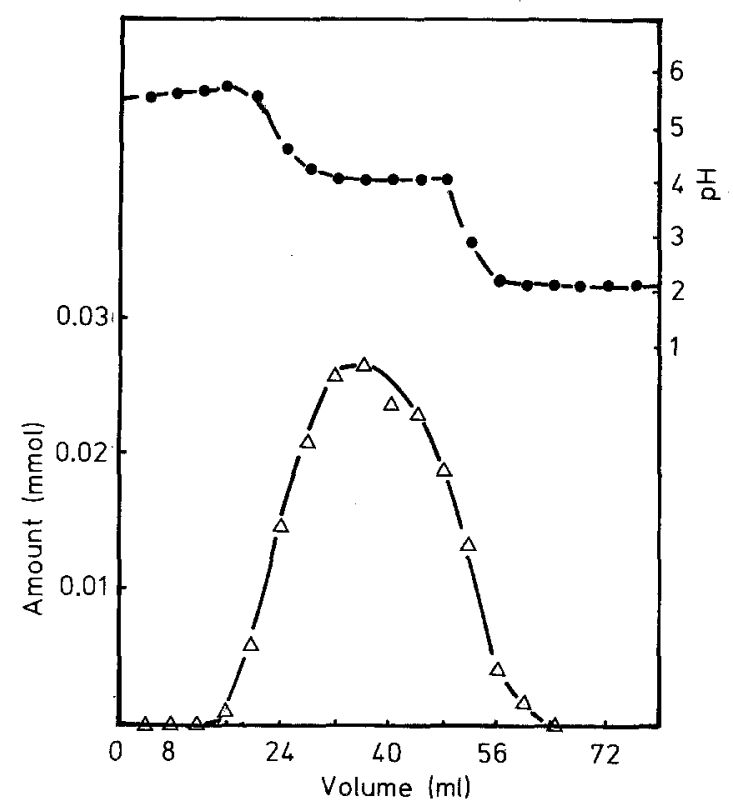

Fig. 7. Changes in $\mathrm{pH}$ and copper(II) content of the collected fractions as a function of the volume of the eluent

Acknowledgement. The financial support of this work by the National Science Council of the Republic of China is gratefully acknowledged.

\section{References}

1. Sahni SK, Reedijk J (1984) Coord Chem Rev 59:1

2. Hulanicki A (1967) Talanta 14:1371

3. Halls DJ (1969) Mikrochim Acta 62

4. Magee RJ (1973) Rev Anal Chem 1:333

5. Scharfe RR, Sastri VS, Chakrabarti CL (1973) Anal Chem 45:413

6. Wyttenbach A, Bajo S (1975) Anal Chem 47:2

7. De AK (1968) Sep Sci 3:103

8. Donaldson EM (1976) Talanta 23:417

9. Donaldson EM (1977) Talanta 24:105

10. Larsson FCV, Lawesson SO (1972) Tetrahedron 28:5341

11. Liu CY, Fan JD, Liu CB (1986) Proc Natl Sci Counc ROC(A) $10: 352$

12. Jensen KA, Buchardt Q, Christophersen C (1967) Acta Chem Scand $21: 1936$

13. Szabadka Ö (1982) Talanta $29: 177$

14. Liu CY, Sun PJ (1986) Fresenius Z Anal Chem 325:553

15. Lih JJ (1987) Thesis, National Taiwan University, Taipei, Taiwan

16. Schmidt EM, Inczédy J, Laki Z, Szabadka Ö (1980) J Chromatogr $201: 73$

Received February 19, 1988 